\title{
SURVEY OF PARASITOIDS AND PREDATORS OF TOMATO LEAF MINER, TUTA ABSOLUTA (MEYRICK) (LEPIDOPTERA: GELECHIIDAE) IN EGYPT
}

\author{
Eman, Abdelmaksoud, M.M.; S. A. El-Refai and Rania, S.A. Rashwan
}

Plant Protection Department- Faculty of Agriculture- Ain Shams University- Cairo- Egypt

Keywords: Tuta absoluta, Lycopersicon esculuntum, Diglyphus, Elasmus, Telenomus, Nesidiocoris tenuis, seasonal abundance, predatory efficiency

\section{ABSTRACT}

The tomato leaf miner, Tuta absoluta (Meyrick) (Lepidoptera: Gelechiidae) is an invasive pest, that caused a significant damage to the tomato crop in the Middle East area. It infests Solanaceae plants especially tomato, Lycopersicon esculuntum Mill. To find parasitoids and predators for biological control of this pest, samples of tomato leaves infested with T. absoluta were collected from Qualiobya and Giza Governorates. Three genera of hymenopterous parasitoids, Diglyphus sp. (Eulophidae), Elasmus spp. (Elasmidae) and Telenomus $\mathrm{sp}$. (Scelionidae) are the first record in Egypt. The predator bug, Nesidiocoris tenuis Reuter (Heteroptera: Miridae) was also recorded. T. absoluta showed two peaks of 30.3 and 25.0 leaf mines/10 leaflets on $7^{\text {th }}$ and $28^{\text {th }}$ of May, 2013, respectively. $N$. tenuis also recorded two peaks of 58.8 and 73.3 nymphs and adults/plant on the same previous dates, respectively. $N$. tenuis was mass reared to evaluate the predatory efficiency of nymph and adult stages on $T$. absoluta eggs. The nymph, adult male and female consumed 113.3, 81.5 and 125.3 eggs of $T$. absoluta, respectively. The $4^{\text {th }}$ nymphal instar devoured the highest number (30.6 eggs), while the $1^{\text {st }}$ nymphal instar ate the lowest (7eggs). Therefore, $N$. tenuis was highly effective in controlling $T$. absoluta eggs under laboratory conditions.

\section{INTRODUCTION}

The tomato leaf miner, Tuta absoluta (Meyrick) (Lepidoptera: Gelechiidae) is a neotropical oli- gophagous pest infesting Solanaceae plants especially tomato, Lycopersicon esculentum Mill. In Europe (Spain), it was recorded for the first time at the end of 2006 (Urbaneja et al 2007). Afterwards, it spread very rapidly along the Mediterranean Basin and in Central Europe and the Middle East (Desneux et al 2010).

Natural enemies such as parasitoids and predators were used successfully in biological control of T. absoluta.Mahdi et al (2011) recorded a parasitoid wasp, Diglyphus sp. (Hymenoptera: Eulophidae) and a predatory bug, Nesidiocoris tenuis Reuter (Heteroptera: Miridae) in Algeria. Giorgini et al (2012) and Zappala et al (2012) found 16 hymenopterous species including Diglyphus crassinervis Erdös belong to 13 genera and 6 families in Italy. Gabarra et al (2013) found 13 larval-pupal parasitoid species including Elasmus phthorimaeae Ferriere (Elasmidae) and D. crassinervis occasionally parasitize $T$. absoluta in Spain. Payer et al (2015) observed that females of Diglyphus isaea Walker are able to predate $T$. absoluta larvae, but they apparently do not parasitize this species in Spain. Al-Gerrawy et al (2013) identified two egg parasitoids, Tricogramma sp. (Tricogrammatidae) and Telenomus sp. (Scelionidae) from T. absoluta in Iraq. Perdikis et al (2016) used different sticky traps to attract the braconid, Dacnusa sibirica Telenga and $D$. isaea parasitizing $T$. absoluta in Greece. They also studied their efficiency in capturing the effective predator $N$. tenuis, whose high population levels may cause damages on the tomato crop.

Molla et al (2009) mentioned that $N$. tenuis was highly effective in controlling $T$. absoluta on tomato under field conditions causing infestation reductions of $97 \%$ in leaflets and $100 \%$ in fruits in Spain. This predator preyed actively on eggs and all larval instars of $T$. absoluta, although it pre- 
ferred first instar larvae under laboratory conditions. Guenaoui and Bensaad (2011) observed young nymphs of $N$. tenuis preying on $T$. absoluta larvae in galleries inside the tomato fruit in France. Molla et al (2011) found that $N$. tenuis can regulate $T$. absoluta populations, because it is able to prey efficiently on pest eggs in Spain. Abbes and Chermiti (2012) used N.tenuis to control T. absoluta on tomato crops in nurseries, greenhouses and open fields in Tunisia. El-Arnaouty and Kortam (2012) recorded $N$. tenuis for the first time in Egypt associated with $T$. absoluta in aubergine and tomato plantations in Giza, Qaluobia and Fayoum Governorates.

The present study aimed to survey parasitoids and predators of $T$. absoluta in some Egyptian Governorates. Seasonal abundance of $N$. tenuis associated with $T$. absoluta and its predatory efficiency on pest eggs were also studied

\section{MATERIAL AND METHODS}

\section{Survey of parasitoids and predators}

Samples of tomato leaves infested with $T$. absoluta were collected from fields at Qualiobya and Giza Governorates during 2012. Leaves were placed in rearing boxes covered with muslin cloth and secured with rubber bands. Emerging parasitoids were collected and kept in ethanol $70 \%$. Parasitoids were identified in Department of Entomology, Faculty of Science, Cairo University. However, predators associated with $T$. absoluta were easily recognized and identified.

\section{Seasonal abundance of N.tenuis associated with $T$. absoluta}

The experiment was carried out in the farm of Faculty of Agriculture at Shoubra Elkheima, Qualiobya Governorate. Seedlings of tomato cultivars were cultivated on $16^{\text {th }}$ April, 2013 in pots in a randomized completed block design. This experiment contained eight tomato cultivars namely, Hybrid Super Strain B, Super set, Hybrid Bito86, Nema guard, Rio grande, Baladi, Red sun and Castle Rock. Each cultivar was replicated five times and each replicate contained eight pots (40 pots / cultivar). The experimental plot received the normal agricultural practices of mechanical weed control, irrigation and fertilizers and was kept free from any pesticide applications.

One week after cultivation, weekly randomized samples of 250 leaflets ( 10 leaflets $x 5$ plants $x 5$ replicates) for each cultivar were taken early in the morning during 10 weeks. Leaflets were kept in tightly closed paper bags and transferred to the laboratory. The pest mine was detected and counted by aid of a stereomicroscope. Total leaf mines of $T$. absoluta and total numbers of $N$. tenuis (nymphs and adults) were estimated on tomato cultivars. Statistical analysis procedures included the simple correlation coefficient and the regression coefficient. All calculations were carried out using SAS program (1988).

\section{Predatory efficiency of N.tenuis on T. absolu- ta eggs}

\subsection{Prey culture}

Tomato leaves infested with T.absoluta were collected from fields of Faculty of Agriculuture, Ain Shams University at Shoubra Elkheima, Qualiobya Governorate. A laboratory stock of the prey was reared in wooden boxes measured $(30 \times 20 \mathrm{~cm})$ with sides made of cloth screen,the top was made of glass to observe emerging insects. Fresh tomato plants were transfered daily to boxes to allow $T$. absoluta laying its eggs on lower surfaces of leaves.

\subsection{Predator culture}

The original culture of $N$. tenuis adults was collected from tomato fields infested with $T$. absoluta and located at Dokki, Giza Governorate in April, 2014 by using sucking traps. N. tenuis adults were kept in rearing glass jars $(20 \times 10 \mathrm{~cm})$ and daily provided with adequate numbers of $T$. absoluta eggs. Glass jars were then covered with muslin cloth tied with rubber bands to prevent insects from escaping and to allow ventilation. Small branches of tomato plants were provided daily as oviposition sites for the predator. Leaves bearing deposited eggs of $N$. tenuis were cut, transferred to clean jars and maintained until hatching under laboratory conditions. Newly hatched nymphs of N.tenuis were daily provided with adequate numbers of prey eggs until adult emergence.

\subsection{The experiment:}

Twenty prey eggs were daily placed on a fresh leaf of tomato provided with a piece of absorbent cotton to avoid drying the eggs and were introduced into a glass tube $(7 \times 2.5 \mathrm{~cm})$ containing one nymph of $N$. tenuis. Ten nymphs (replicates) of the 
(meyrick) (lepidoptera: gelechiidae) in egypt

predator were maintained to evaluate their predatory efficiency. Number of eggs consumed by $N$. tenuis nymphs was recorded daily and replaced with other freshly deposited eggs. Durations of five nymphal instars of the predator were also estimated. This experiment was examined daily until adult emergence. The previous technique was also conducted on 10 adults of $N$. tenuis.

\section{RESULTS AND DISCUSSION}

\section{Survey of parasitoids and predators}

\subsection{Parasitoids}

Three different specimens of hymenopterous parasitoids were obtained from $T$. absoluta and identified to the genus level. Larval parasitoids of T. absoluta include Diglyphus sp. (Eulophidae) and Elasmus spp. (Elasmidae). The egg parasitoid is Telenomus sp. (Scelionidae). These parasitoids are the first record in Egypt.

\subsubsection{Diglyphus sp.}

Diglyphus sp. is a larval ectoparasitoid of $T$. absoluta. This result agrees with that of Lopez et al (2011) who reported that $D$. isaea is a larval ectoparasitoid of T.absoluta in Spain. Mahdi et al (2011) recorded Diglyphus sp.parasitizing T.absoluta in Algeria. Giorgini et al (2012) and Zappala et al (2012) found 16 hymenopterous species including $D$. crassinervis belong to 13 genera and 6 families in Italy. Gabarra et al (2013) found 13 larval-pupal parasitoid species including D.crassinervis occasionally parasitize $T$. absoluta in Spain. Perdikis et al. (2016) recorded D. isaea parasitizing $T$. absoluta in Greece. On the other hand, Payer et al. (2015) observed that females of $D$. isaea are able to predate $T$. absoluta larvae, but they apparently do not parasitize this species in Spain (Fig.1).

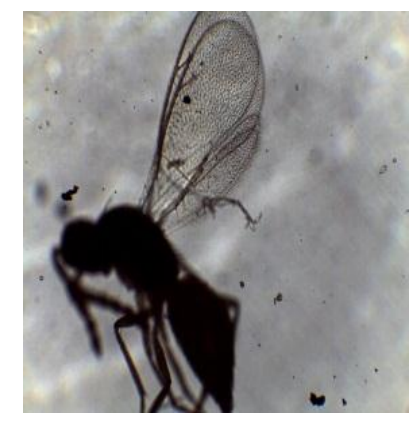

Fig.1. Adult of Diglyphus sp.

\section{Description}

Fore wing with submarginal vein (SMV) with 3 or more setae dorsally. Postmarginal vein (PMV) present: at most 1.25 times longer than stigmal vein (STV), often equal or shorter. Scape usually slender, sometimes swollen and not exceeding apex of vertex. Funicle 2-segmented and club 3segmented both in male and female. Fronto-facial suture (ffs) adjacent anterior ocellus and one transverse groove (gr) between eye margin and scrobal cavity placed about halfway between ocellus and torulus. Malar sulcus present and straight. Propleura separated posteriorly and not covering prosternum.Notauli either incomplete, or complete and curving to meet axilla. Scutellum with 2 pair of setae and with 1 pair of longitudinal grooves. Propodeum with or without median carina and always with outplicae. Petiole not distinct.Coloration entirely or prevalently metallic (Reina and La Salle, 2003).

\subsubsection{Elasmus spp.}

There are two unidentified species of Elasmus. Elasmus sp. is a larval-pupal parasitoid of T.absoluta. Giorgini et al (2012) and Zappala et al (2012) found 16 hymenopterous species including Elasmus sp. belong to 13 genera and 6 families in Italy.Gabarra et al (2013) found 13 larvalpupal parasitoid species including E. phthorimaeae occasionally parasitize T. absoluta in Spain (Fig.2).

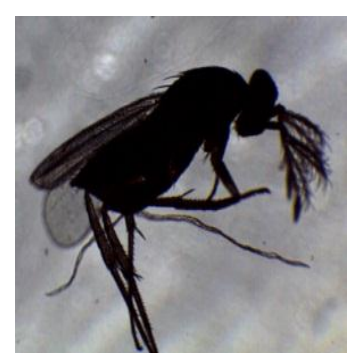

Species A

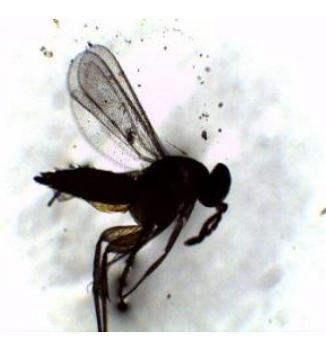

Species B
Fig. 2. Adult of Elasmus spp.

\section{Description}

Fore wing densely setose and wedge-shaped, with elongate marginal vein, short postmarginal, and slightly reduced stigmal vein. Female funicle 3segmented with two anelli and 3-segmented clava; male funicle 4-segmented, F1-F3 with branches, clava 2-segmented with pronounced apical sensi- 
lum. Mesosoma densely setose, metasoma subsessile and gaster triangular in cross. Metanotum projecting as flat, triangular, often translucent plate over propodeum. Dorsal metanotal lamella projecting posterior over propodeum with partial and complete lateroventral keels. Scutellum with 2 pairs of long setae. Metacoxa greatly enlarged and flattened plate-like hind tibia with short bristles forming distinct diamond-shaped or undulating pattern (Yefremova and Strakhova, 2010).

\subsubsection{Telenomus sp.}

Telenomus sp. is an egg parasitoid of T.absoluta. Al-Gerrawy et al (2013) also recorded Telenomus sp. parasitizing T.absoluta eggs in Iraq (Fig.3).

\section{Description}

Small wasp, almost always black or dark brown. Female antenna with 5-segmented club (when present), male antenna 12-segmented. Frons smooth (Polaszek and Kimani, 1990).

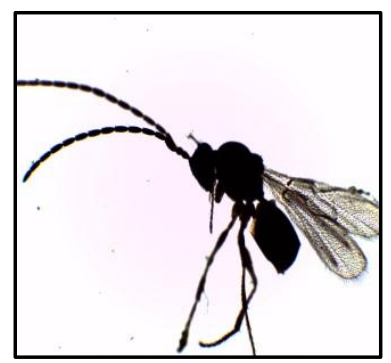

Fig. 3. Adult of Telenomus sp.

\subsection{Predator}

\section{N. tenuis}

N.tenuis was the only predator species, that was found in the survey. It is an important predator of $T$. absoluta eggs. In this context, N.tenuis was recorded associating with $T$. absoluta on tomato by several authors in different countries (Arno et al 2009 in Spain; Cabello et al 2009 in Spain; Molla et al 2009 in Spain; Arno and Gabarra, 2010 in Spain; Guenaoui and Bensaad, 2011 in France; Mahdi et al 2011 in Algeria; Molla et al 2011 in Spain; El-Arnaouty and Kortam, 2012 in Egypt; Biondi et al 2013 in France; Sohrabi and Hosseini, 2015 in Iran) (Fig. 4).

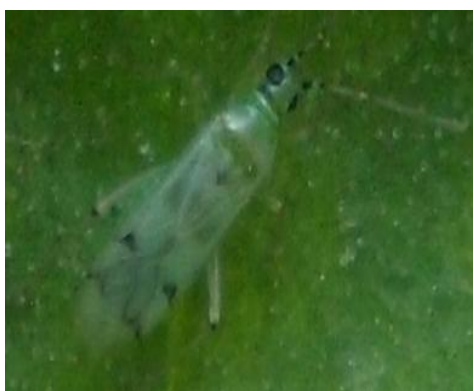

Fig. 4. Adult of N. tenuis

\section{Description}

Body size 3-3.3 mm. Pale whitish green. Ocular index: 1.3-1.5. Left parameter very slender, strongly curved sickle shaped. Middle of the first segment, and base of the second segment of antenna-black. A dark ring at the apex of the 2nd antennal segment, 3rd and 4th segment - brown. At the rear edge of the corium there was a small dark brown spot and at the tip of the cuneus there was a small dark brown spot. Membrane - gray, veins - brown. Base of the tibia (knee) narrowly black (Hosseini, 2013).

\section{Seasonal abundance of $\mathbf{N}$. tenuis associat- ed with $T$. absoluta}

Data tabulated in Table (1) and Figure (5) revealed that T.absoluta appeared one week earlier than $N$. tenuis. The population of $T$. absoluta had two peaks of 30.3 and 25.0 leaf mines/10 leaflets on $7^{\text {th }}$ and $28^{\text {th }}$ of May, 2013, respectively. N.tenuis similarly had two peaks of 58.8 and 73.3 nymphs and adults/plant on the same previous dates, respectively.

This predator was significantly and positively correlated with T.absoluta $(r=+0.87$ and $b=0.26)$.

\section{Predatory efficiency of $N$. tenuis on $T$. $a b$ - soluta eggs}

Mean numbers of eggs consumed by nymph and adult stages of N.tenuis are shown in Table (2). The adult female consumed a higher number (125.3 eggs) than the adult male (81.5 eggs). The $4^{\text {th }}$ nymphal instar devoured the highest number (30.6 eggs), while the $1^{\text {st }}$ nymphal instar ate the lowest (7 eggs). $N$. tenuis was highly effective in controlling $T$. absoluta eggs. Several authors reported that N.tenuis preyed actively on T.absoluta eggs and could regulate pest populations (Arno, et al 2009; Molla et al 2009; Arno \& Gabarra, 2010; Molla et al 2011 and Biondi et al 2013). 
Table 1. Seasonal abundance of N.tenuis associated with $T$. absoluta

\begin{tabular}{|c|c|c|}
\hline Inspection date & $\begin{array}{c}\text { Leaf mines of } \boldsymbol{T} \\
\text { absoluta } / \mathbf{1 0} \\
\text { leaflets }\end{array}$ & $\begin{array}{c}\text { N. tenuis } \\
\text { (nymphs+ } \\
\text { adults) /plant }\end{array}$ \\
\hline April,23th & 0 & 0 \\
$30^{\text {th }}$ & $10.8 \pm 0.2$ & 0 \\
May, $7^{\text {th }}$ & $30.3 \pm 0.3$ & $58.8 \pm 0.6$ \\
$14^{\text {th }}$ & $13 \pm 0.3$ & $25.5 \pm 0.2$ \\
21 th & $24.3 \pm 0.6$ & $48.8 \pm 0.5$ \\
$28^{\text {th }}$ & $25 \pm 0.3$ & $73.3 \pm 0.9$ \\
June,4 $^{\text {th }}$ & 0 & 0 \\
$11^{\text {th }}$ & 0 & 0 \\
$18^{\text {th }}$ & 0 & 0 \\
$25^{\text {th }}$ & 0 & 0 \\
Total & 103.3 & 206.4 \\
Mean & 10.3 & \\
\hline Correlation coeffi- & & \\
cient(r) & $0.87+$ & \\
\hline Regression coeffi- & & \\
cient (b) & $0.26+$ & \\
\hline
\end{tabular}

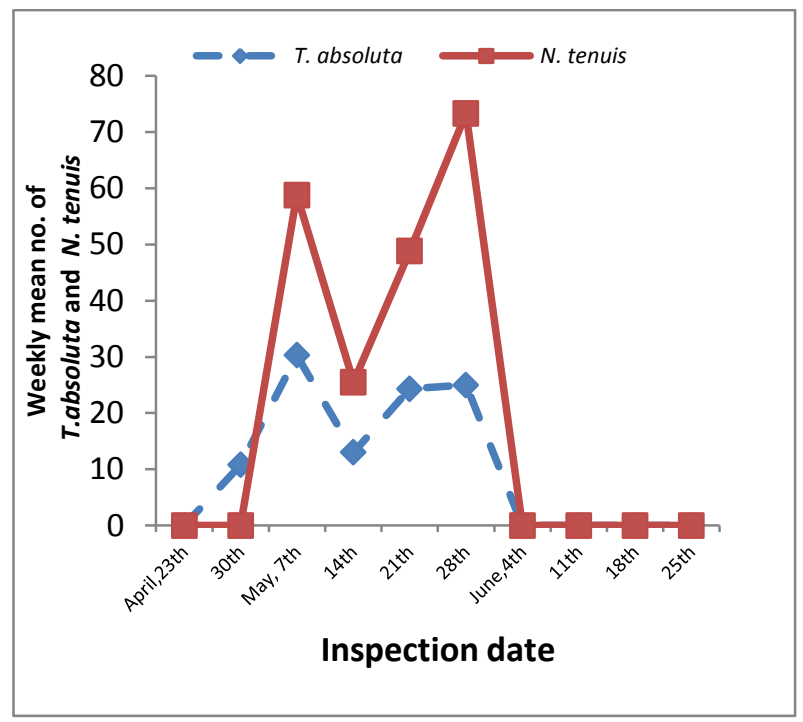

Fig. 5. Seasonal abundance of $N$. tenuis associated with $T$. absoluta

Table 2. Predatory efficiency and durations of nymphal instars and adults of $\boldsymbol{N}$. tenuis reared on $T$. absoluta eggs

\begin{tabular}{|c|c|c|c|c|c|c|c|}
\hline \multirow[b]{2}{*}{ Predator stages } & \multicolumn{5}{|c|}{ Nymphal instar } & \multicolumn{2}{|c|}{ Adult } \\
\hline & $1^{\text {st }}$ & $2^{\text {nd }}$ & $3^{\text {rd }}$ & $4^{\text {th }}$ & $5^{\text {th }}$ & Male & Female \\
\hline $\begin{array}{l}\text { No. of prey eggs con- } \\
\text { sumed (Mean+S.E.) }\end{array}$ & $7 \pm 0.2$ & $20.5 \pm 0.5$ & $26.6 \pm 0.4$ & $30.6 \pm 0.6$ & $28.6 \pm 0.5$ & $81.5 \pm 1.2$ & $125.3 \pm 0.3$ \\
\hline Duration (Mean+S.E.) & $2.1 \pm 0.03$ & $2.2 \pm 0.04$ & $2.2 \pm 0.04$ & $2.4 \pm 0.06$ & $3.3 \pm 0.05$ & $7.5 \pm 0.65$ & $12.3 \pm 0.4$ \\
\hline
\end{tabular}

\section{ACKNOWLEDGEMENT}

The writers express their deep thanks to Prof. Dr. Nevin, S.G., Department of Entomology, Faculty of Science, Cairo University for identifying genera of parasitoids and to Prof. Dr. Hekal, A.M., Department of Plant Protection, Faculty of Agriculture, Ain Shams University for revising the identification.

\section{REFERENCES}

Abbes, K. and Chermiti B. 2012. Failure of the biological control of Tuta absoluta using the predator Nesidiocoris tenuis in a protected tomato crop: analysis of factors. IOBC/WPRS Bull., 80, 231-236.

Al-Gerrawy, A.J.; H.K. Al-Zubaidy and N.N. Hama 2013. First record of important natural enemies on tomato borer Tuta absoluta (Meyrick) (Lepidoptera: Gelechiidae) in greenhouses in middle of Iraq. Second Scientific Conference, Fac. Agric., Carbelaa Univ., pp. 953-960.
Arnó, J. and R. Gabarra (2010). Controlling Tuta absoluta, a new invasive pest in Europe. Food Quality and Safety (ENDURE). www.endurenetwork.eu

Arno, J.; Sorribas R.; Prat M.; M. Matas; C. Pozo; D. Rodriguez; Garreta A.; Gomez A. and Gabarra R. 2009. Tuta absoluta, a new pest in IPM tomatoes in the northeast of Spain. IOBC/WPRS Bull., 49, 203-208.

Biondi, A.; Desneux N.; Amiens-Desneux E.; Siscaro G. and Zappala L. 2013. Biology and developmental strategies of the palaearctic parasitoid Bracon nigricans (Hymenoptera: Braconidae) on the neotropical moth Tuta $a b$ soluta (Lepidoptera: Gelechiidae). J. Econ. Entomol., 106(4), 1638-1647.

Cabello, T.; Gallego J.R.; Fernandez-Maldonado F.J.; Soler A.; Beltran D.; Parra A. and Vila E. 2009.The damsel bug, Nabis pseudoferus (Hem.: Nabidae) as a new biological control agent of the South American Tomato Pinworm, Tuta absoluta (Lep.: Gelechiidae) in tomato 
crops of Spain. IOBC/WPRS Bull., 49, 219223.

Desneux, N.; Wajnberg E.; Wyckhuys K.A.G.; Burgio G.; Arpaia S.; Narva'ez-Vasquez C.A.; J. Gonza'lez-Cabrera; Diana C. Ruescas; Tabone E.; Frandon J.; Pizzol J.; Poncet C.; Cabello T. and Urbaneja A. 2010. Biological invasion of European tomato crops by Tuta absoluta: ecology, geographic expansion and prospects for biological control. J. Pest Sci., 83,197-215.

El-Arnaouty, S.A. and Kortam M.N. 2012. First record of the mirid predatory species, Nesidiocoris tenuis Reuter (Heteroptera: Miridae) on the tomato leafminer, Tuta absoluta (Meyrick) (Lepidoptera: Gelechiidae) in Egypt. Egypt. J. Biol. Pest Cont., 22(2), 223-224.

Gabarra, R.; Arno J.; Lara L.; Verdu M.J.; Ribes A.; Beitia F.; Urbaneja A.; Te'llez M.M.; Molla' O. and Riudavets J. 2013. Native parasitoids associated with Tuta absoluta in the tomato production areas of the Spanish Mediterranean Coast. Bio Control, 59, 45-54.

Giorgini, M.; Bernardo U. and Pedata P.A. 2012. The parasitoid complex of Tuta absoluta (Meyrick) in Italy. Italia. Entomol. Anno, 60, 77-84.

Guenaoui, Y. and Bensaad R. 2011. Behaviour of Tuta absoluta larvae attacking tomato fruit. Les Cochenilles: ravageur principal ou secondaire. 9eme Conference Internationale sur les Ravageurs en Agriculture, Sup Agro, Montpellier, France, 25-27 Octobre, pp. 318323.

Hosseini, R. 2013. On the tribe Dicyphini (Hemiptera: Heteroptera: Miridae: Bryocorinae) in Guilan province and adjacent area (Iran). Entomofauna, 34 (11), 157-158.

Lopez, J.A.; Amor F.; Bengochea P.; Medina P.; Budia F. and Viñuela E. 2011. Short communication. Toxicity of emamectin benzoate to adults of Nesidiocoris tenuis Reuter, Macrolophus pygmaeus (Rambur) (Heteroptera, Miridae) and Diglyphus isaea Walker (Hymenoptera, Eulophidae) on tomato plants Semi-field studies. Span. J. Agric. Res., 9(2), 617-622.

Mahdi, K.; Doumandji-Mitiche B.; Ababsia A. and Doumandji S. 2011. Natural enemies of the tomato leaf miner Tuta absoluta (Meyrick, 1917) in Algeria: prospects for biological control. 4eme Conference Internationale sur les Methodes Alternatives en Protection des Cultures. Evolution des cadres reglementaires europeen et francais. Nouveaux moyens et strategies Innovantes, Nouveau Siecle, Lille, France, pp. 561-567.
Molla, O.; Monton H.; Vanaclocha P.; Beitia F. and Urbaneja A. 2009. Predation by the mirids Nesidiocoris tenuis and Macrolophus pygmaeus on the tomato borer Tuta absoluta. IOBC/WPRS Bull., 49, 209-214.

Molla, O.; Gonzalez-Cabrera J. and Urbaneja A. 2011. The combined use of Bacillus thuringiensis and Nesidiocoris tenuis against the tomato borer Tuta absoluta. BioControl, 56(6), 883-891.

Payer, R.; Figueiredo E. and Mexia A. 2015. Evaluation of parasitism and predation of Tuta absoluta (Meyrick, 1917) (Lepidoptera: Gelechiidae) by Diglyphus isaea. Shilap Revta. Lepid., 43 (170), 173-179.

Perdikis, D. Ch.; Arvaniti K.A. and Papadimitriou D.M. 2016. Effects of sticky traps on Dacnusa sibirica, Diglyphus isaea and Nesidiocoris tenuis. Entomol. Hellen., 25 : XX-XX. (in Press).

Polaszek, A. and Kimani S.W. 1990.Telenomus species (Hymenoptera: Scelionidae) attacking eggs of pyralid pests (Lepidoptera) in Africa. A review and guide to identification. Bull. Ent. Res., 80, 57-71.

Reina, P. and La Salle J. 2003. Key to the world genera of Eulophidae Parasitoids (Hymenoptera) of Leafmining Agromyzidae (Diptera).

http://www.ento.csiro.au/science/eulophids.htm I (CSIRO Entomology, GPO Box 1700, Canberra, ACT 2601, Australiajohn.lasalle@csiro.au)

SAS instituite 1988. SAS/stat user's guide. 6.03 ed. SAS institute Cary, Nc.

Sohrabi, F. and Hosseini R. 2015. Nesidiocoris tenuis (Reuter) (Heteroptera: Miridae), a predatory species of the tomato leafminer, Tuta $a b$ soluta (Meyrick) (Lepidoptera: Gelechiidae) in Iran. J. Plant Prot. Res., 55(3), 322-323.

Urbaneja, A.; Vercher R.; Navarro V.; Garcı'a F. Marı' and Porcuna J.L. (2007). La polilla del tomate, Tuta absoluta.Phytoma España, 194,16-23.

Yefremova Z.A. and Strakhova I.S. 2010. A review of the species of the genus Elasmus Westwood(Hymenoptera: Eulophidae) from Russia and neighboring countries. Entomol. Rev., 90(7), 903-926.

Zappalà, L.; Bernardo U.; Biondi A.; Cocco A.; Deliperi S.; Delrio G.; Giorgini M.; Pedata P.; Rapisarda C.; Garzia G.T. and Siscaro G. 2012. Recruitment of native parasitoids by the exotic pest Tuta absoluta in Southern Italy. Bull. Insectol. 65 (1), 51-61. 